\title{
Molecular evidence of Bartonella spp. in free-living opossums (Didelphimorphia: Didelphidae) from peri-urban Atlantic Forest fragments of Brazil
}

\author{
Amanda Alcantara ${ }^{1}$, Helena Thoma ${ }^{2}$, Sabrina Campos $^{1}$, Rosemeri Teixeira ${ }^{1}$, Hans Lima ${ }^{1}$, \\ Jeferson Pires ${ }^{3}$, Renata Moraes ${ }^{4}$, and Aline Souza ${ }^{1}$ \\ ${ }^{1}$ Universidade Federal Fluminense \\ ${ }^{2}$ Universidade Federal do Rio de Janeiro \\ ${ }^{3}$ Universidade Estacio de Sa - Campus Reboucas-Rio Comprido \\ ${ }^{4}$ Universidade de Vassouras
}

September 16, 2020

\begin{abstract}
Many emerging infectious diseases are zoonotic and transmitted by an arthropod vector; thus, the Global One Health perspective is necessary for a better understanding of these diseases. Bartonellosis, one of those emerging infectious diseases, is caused by bacteria of the genus Bartonella, and can have different clinical manifestations in humans and animals. Opossums and their ectoparasites have been linked to human-wildlife conflicts. Knowing this, we aimed to evaluate infection by Bartonella spp. in free-living opossums seized or rescued from Atlantic Forest biome of Rio de Janeiro (southeastern Brazil). Whole blood was obtained from seven Didelphis aurita and eight D. albiventris, and DNA was assessed by conventional and quantitative polymerase chain reactions (PCR and qPCR). Positivity was achieved in $40.0 \%$ (PCR) and $46.7 \%$ (qPCR) of the samples, revealing, possibly for the first time, the presence of Bartonella spp. DNA in opossums from peri-urban areas of Atlantic Forest biome. Studies should continue, in order to elucidate synanthropic mammals importance in bartonellosis epidemiology.
\end{abstract}

\section{Main document}

\section{Introduction}

Opossums (Didelphis spp.) are neotropical marsupials of the order Didelphimorphia, family Didelphidae. Among the species that occur in Brazil, two can be easily found in the great Brazilian biomes, D. aurita (black-eared opossum) and D. albiventris (white-eared opossum) (Aléssio et al., 2005; Moura et al., 2009; Paglia et al., 2012). These mammals have opportunistic habits, and can live in wild, rural and urban environments, maintaining contact with other animals and human beings (Lucheis et al., 2009; Tarragona et al., 2011). Notably, white-eared opossum is widely distributed in Brazilian biomes and is strongly adapted to highly degraded areas, as well as urban forest fragments (Aléssio et al., 2005).

This type of behavior, called synanthropic, places opossums as a key group in the connection between wild and domestic epidemiological cycle of emerging parasites and microorganisms (Forzanari et al., 2011; Tarragona et al., 2011). For example, opossums and its most common ectoparasite, Ctenocephalis felis flea, have been epidemiologically linked to flea-borne pathogens transmission and human-wild life conflicts in residential environments (Krueger et al., 2016).

Studies support that cat flea (C. felis) is the major competent vector for Bartonella henselae, B. clarridgeae , B. koehlerae, and potentially B. quintana (Pennisi et al., 2013; Zangwill, 2013). Those species among others 
belong to the $\alpha$-proteobacteria, are hemotropic, short and pleomorphic Gram-negative bacteria that cause intra-erythrocytic infections in animals and humans (Jacomo et al., 2002; Deng et al., 2012). Bartonella species appear to be highly adapted to one or few reservoir hosts, within which these bacteria have coevolved and thence remain for long periods in bloodstream (Kaiser et al., 2011; Harms and Dehio, 2012).

Until 1990, only two diseases were linked to Bartonella species, Carrión disease (B. bacilliformis ) and Trench fever (B. quintana) (Karem et al., 2000). Since then, many other Bartonellae have been identified as causative agents of diseases in animals and humans (Iannino et al., 2018). Importantly, the list of mammalianadapted Bartonella species continues to grow, as well as the number of human disease associated with genus Bartonella (Kaiser et al., 2011; Harms and Dehio, 2012; Buffet et al., 2013).

Currently, Cat-scratch disease (CSD) is the most common human disease caused by Bartonella species, including B. henselae, andB. clarridgeiae (Iannino et al., 2018). Clinical manifestation of CSD depends on patient immune status, and pet cats and dogs often develop similar manifestations as humans (Chomel et al., 2009; Breitschwerdt et al., 2010; Beerlage et al., 2012). Typical CSD denotes a self-limiting illness characterized by fever and lymphadenopathy; however, atypical manifestations can occur (Jacomo et al., 2002; Breitschwerdt et al., 2010; Zangwill, 2013).

Bartonella genus has already been isolated or detected in domestic and wild animals worldwide, including bats, birds, canids, cattle, deer, felids, horses, marine mammals, rodents, sheep and reptiles (Deng et al., 2012). Little is known about wild reservoirs of these bacteria in Brazil, but recently, a study reported $B$. henselae and B. clarridgeiae in domestic cats from an Atlantic Forest area of Rio de Janeiro state (RJ), where humans, domestic, synanthropic and wild animals can easily interact (Silva et al., 2019). Opossums are often identified as likely maintainers of infectious agents with zoonotic potential (Abel et al., 2000; Ruiz-Piñaand Cruz-Reyes, 2002; Fornazari et al., 2011; Pena et al., 2011).

Considering the growing spectrum of animal reservoir hosts for Bartonella species, and given the presence of Bartonellaspp. in RJ state, this study aimed to evaluate natural infections by those bacteria in free-ranging opossums that lived in peri-urban areas of the Atlantic Forest of RJ, Brazil.

\section{Materials and Methods}

This cross-sectional study was approved by Ethics Committee on Animal Use (CEUA) of Universidade Federal Fluminense (UFF) (8405150718) and licensed by Biodiversity Information and Authorization System (SISBIO/IBAMA63464-2).

Adult and young free-living opossums were included in this study. Animals were seized or rescued by environment alauthorities and samples were collected at wild life rehabilitation facilities of Universidade Estácio

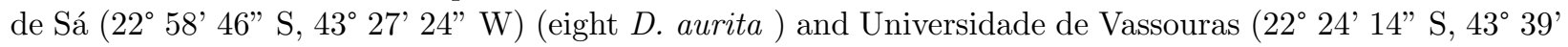
45 " W) (sevenD. albiventris ), both located in RJ state, Brazil. Animals were physically restrained and venipuncture was proceeded from ventral caudal vein, obtaining up to $1.0 \mathrm{~mL}$ of blood, which was immediately placed in ethylenediaminetetraacetic acid (EDTA) tubes.

DNA extraction was performed with the Master Pure ${ }^{\mathrm{TM}}$ DNA Purification Kit for Blood Version (Epicentreß, Madison, Wisconsin, USA). In order to avoid false negative results, DNA samples were tested for presence of amplifiable DNA using the primer set GAPDH-F (5'-CCTTCATTGACCTCAACTACAT-3') and GAPDH-R (5'-CCAAAGTTGTCATGGATGACC-3'), resulting in amplification of a 399 bp fragment of the housekeeping gapdh gene, encoding glyceraldehyde-3-phosphate dehydrogenase enzyme, which is present in all mammals (Birkenheuer et al., 2003).

Subsequently, presence of bacterial DNA was tested by conventional and quantitative polymerase chain reactions (PCR and $\mathrm{qPCR}$ ) targeting a $365 \mathrm{bp}$ fragment of Bartonella spp. citrate synthase (gltA ) gene with primers BhCS781p (5' GGGGACCAGCTCATGGTGG 3') and BhCS1137n (5' AATGCAAAAAGAACAGTAAACA 3'), as previously proposed (Norman et al., 1995). Positive (purified DNA of B. henselae extracted from a naturally infected cat) and negative (nuclease-free water) controls were used for each reaction. Amplicons underwent electrophoresis on $1.5 \%$ agarose gel stained with ethidium bromide. 


\section{Results and discussion}

Conventional PCR identified Bartonella spp. DNA in 40\% of opossums (6/15). All positive samples belonged to $D$. auritaspecies, representing $85.7 \%$ among evaluated samples of this species (6/7). Using the qPCR assays, we found $46.7 \%(7 / 15)$ of positive results. It is important to note that simultaneous positivity in both PCR and qPCR assays was observed in the same specimens of D. aurita. One animal, of D. albiventris species, was negative in conventional PCR and positive in qPCR.

This is, for the best of author's knowledge, the first report of naturalBartonella spp. infection in opossums in areas of Atlantic Forest biome at RJ state. Although not expected, the high frequency of PCR positive animals may be justified, since other studies have successfully demonstrated presence of Bartonella spp. in wild mammals and ectoparasites in different Brazilian biomes (Favacho et al., 2015; Sousa et al., 2018). In addition, $C$. felis, the main vector involved in Bartonella spp. transmission among cats, has been observed in opossums from RJ (Oliveira et al., 2010). It is also necessary to emphasize the occurrence of $B$. henselae and B. vinsoniisubsp. arupensis in C. felis collected from the Virginia opossum, D. virginiana, from California, USA (Reeves et al., 2005; Krueger et al., 2016). According to Reeves et al., 2005, the presence of B. henselae in cat fleas collected from opossums, implicates both $C$. felis and opossums in maintaining this pathogen.

Recently, Silva et al., 2019 revealed the natural infection by B.henselae and B. clarridgeiae in stray cats that illegally inhabited a preserved area of Atlantic Forest in RJ State. According to the authors, study area harbored a wide variety of fauna and flora, as well as allowed human visitation and ecotourism. Although cats are important hosts for B. henselae , B. clarridgeiae, and B. koehlerae, there are CSD patients that deny the occurrence of bite, scratch or even contact with cats, making the possibility of transmission from other animal hosts more and more probable (Breitschwerdt, 2014).

In this context, roaming animal population, such as that found by Silva et al., 2019, can be a source of infection for pet cats. Added to this, we suggest that in epidemiological cycle of bartonellosis, cat flea is probably the bridge that links wild mammals (such as D. auritaand D. albiventris ) to domestic or stray cats and these latter to humans.

Temperature and relative humidity are relevant factors for successful reproduction, development, and survival of fleas (Dryden et al., 1994), and, apparently, cats are more parasitized by fleas during summer and autumn months (Farkas, 2009). Given that, several places of Atlantic Forest biome in RJ may provide a favorable scenario for interaction among Bartonella -infected cats, their fleas and susceptible opossums.

We concluded that Bartonellae have many important human-animal-environment aspects. For this reason, it is crucial to adopt the One Health strategy for emerging zoonosis management in stray animal populations and synanthropic animals, involving collaborative work of environmentalists, medical and veterinary researchers. The study continuity is necessary to identify Bartonella species involved, potential risk factors and epidemiological function of synanthropic mammals (including opossums) as reservoirs in maintenance and transmission of these bacteria.

\section{Acknowledgements}

We are grateful to Pro-Reitoria de Pesquisa, Pos-Graduacao e Inovacao, Universidade Federal Fluminense (Proppi/UFF) for financial support and scholarship.

\section{Conflict of Interest Statement}

The authors declare no conlict of interest.

\section{References}

Abel IS, Almeida Jr DE, Fonseca AH, Soares CO, Ishikawa MM (2000)Borrelia sp. in naturally infected Didelphis aurita (Wied, 1826) (Marsupialia: Didelphidae). Brazilian Archives of Biology and Technology 43(3):1-6. doi:10.1590/S1516-89132000000300010 
Alessio FM, Pontes ARM, Silva VL (2005) Feeding by Didelphis albiventris on treegum in the Northeastern Atlantic Forest of Brazil. Mastozoologia Neotropical 12(1): 53-56

Beerlage C, Varanat M, Linder K, Maggi RG, Colley J, Kempf AJK, Breitschwerdt EB (2012) Bartonella vinsonii subsp. berkhoffii andBartonella henselae as potential causes of proliferative vascular disease in animals. Medical Microbiology and Immunology 201(3):319-326. doi: 10.1007/s00430-012-0234-5.

Birkenheuer AJ, Levy MG, Breitschwerdt EB (2003) Development and evaluation of a seminested PCR for detection and differentiation ofBabesia gibsoni (Asiangenotype) and B. canis DNA in canine blood samples. Journal of Clinical Microbiology. 41(9):4172-4177. doi: 10.1128/JCM.41.9.4172-4177.2003

Breitschwerdt EB, Maggi RG, Chomel BB, Lappin MR (2010) Bartonellosis: an emerging infectious disease of zoonotic importance to animals and human beings. Journal of Veterinary Emergency and Critical Care 20(1):8-30. doi: 10.1111/j.1476-4431.2009.00496.x

Breitschwerdt EB (2014) Bartonellosis: one health perspectives for an emerging infectious disease. ILAR Journal 55(1):46-58. doi: 10.1093/ilar/ilu015

Buffet JP, Kosoy M, Vayssier-Taussat M (2013) Natural history ofBartonella -infecting rodents in light of new knowledge on genomics, diversity and evolution. Future Microbiology 8(9):1117-1128. doi: $10.2217 /$ fmb.13.77

Chomel BB, Kasten RW, Williams C, Wey AC, Henn JB, Maggi R, Carrasco S, Mazet J, Boulouis HJ, Maillard R, Breitschwerdt EB (2009)Bartonella endocarditis: A pathology shared by animal reservoirs and patients. Annals of the New York Academy of Sciences 1166:120-126. doi: 10.1111/j.1749-6632.2009.04523.x

Deng H, Le Rhun D, Buffet J-PR, Cotte V, Read A, Birtles RJ, Vayssier-Taussat M (2012) Strategies of exploitation of mammalian reservoirs by Bartonella species. Journal Of Veterinary Research 43(1):15. doi: 10.1186/1297-9716-43-15

Dryden MW \& Rust MK (1994) The cat flea: biology, ecology and control. Veterinary Parasitology 52(12):1-19. doi: 10.1016/0304-4017(94)90031-0

Farkas R, Gyurkovszky M, Solymosi N, Beugnet F (2009) Prevalence of flea infestation in dogs and cats in Hungary combined with a survey of owner awareness. Medical and Veterinary Entomology 23(3):187-194. doi: $10.1111 / \mathrm{j} .1365-2915.2009 .00798 . x$

Favacho ARM, Andrade MN, Oliveira RC, Bonvicinob CR, D'Andrea PS, Lemos ERS (2015) Zoonotic Bartonella species in wild rodents in the state of Mato Grosso do Sul, Brazil. Microbes and Infection 17(11-12):889-892. doi: $10.1016 / \mathrm{j}$.micinf.2015.08.014

Fornazari F, Teixeira CR, Silva RC, Leiva M, Almeida SC, Langoni H (2011) Prevalence of Toxoplasma gondii among brazilian white eared opossums (Didelphis albiventris ). Veterinary Parasitology 179 (1-3):238-241. doi:10.1016/j.vetpar.2011.02.005

Harms A, Dehio C (2012) Intruders below the radar: molecular pathogenesis of Bartonella spp. Journal of Clinical Microbiology 25(1):42-78. doi: 10.1128/CMR.05009-11

Iannino F, Salucci S, Di Provvido A, Paolini A, Ruggieri E.Bartonella Infections in Humans Dogs and Cats. Vet Ital. 2018, 54(1):63-72. doi: 10.12834/VetIt.398.1883.2.

Jacomo V, Kelly PJ, Raoult D. Natural history of Bartonella infections (an exception to Koch's postulate). Clin Diagn Lab Immunol. 2002;9:8-18. doi:97 10.1128/CDLI.9.1.8-18.2002

Kaiser PO, Riess T, O'Rourke F, Linke D, Kempf VA (2011)Bartonella spp.: Throwing light on uncommon human infections. International Journal of Medical Microbiology 301(1):7-15. doi: 10.1016/j.ijmm.2010.06.004 
Karem KL, Paddock CD, Regnery RL (2000) Bartonella henselae ,B. quintana, and B. bacilliformis : historical pathogens of emerging significance. Microbes and Infection 2(10):1193-1205. doi: 10.1016/s12864579(00)01273-9

Krueger L, Bai Y, Bennett S, Fogarty C, Sun S, Kosoy M, Maina A., Nelson K, Platzer E, Oiskowicz L, Richards AL, Shariar F, Trinidad A, Cummings R (2016) Identification of zoonotic and vector-borne infectious agents associated with Opossums (Didelphis virginiana) in residential neighborhoods of Orange County, California. Proceedings of the Vertebrate Pest Conference 27:268-279

Lucheis SB, Hernandes GS, Lenharo DK, Santiago MEB, Baldini-Peruca LC (2009) Are opossums capable of transmiting leptospirosis in urban areas? Journal of Venomous Animals and Toxins including Tropical Diseases 15(3):370-473. doi:10.1590/S1678-91992009000300002

Moura MC, Vieira MV, Cerqueira R (2009) Occasional intraguild predation structuring small mammal assemblages: the marsupial Didelphis aurita in the Atlantic Forest of Brazil. Austral Ecology 34(5):481-489. doi:10.1111/j.1442-9993.2009.01948.x

Norman AF, Regnery R, Jameson P, Greene C, Krause DC (1995) Differentiation of Bartonella-like isolates at the species level by PCR-restriction fragment length polymorphism in the citrate synthase gene. Journal of Clinical Microbiology 33(7):1797-1803. doi: 10.1128/JCM.33.7.1797-1803.1995

Oliveira HH, Almeida AB, Carvalho RW, Gomes V, Serra-Freire NM, Quinelato I, Carvalho AG (2010) Siphonaptera of small rodents and marsupials in the Pedra Branca State Park, State of Rio de Janeiro, Brazil. Brazilian Journal of Veterinary Parasitology 19(1):49-54 doi: 10.4322/rbpv.01901009

Paglia AP, Fonseca GAB, Rylands AB, Herrmann G, Aguiar LM, Chiarello AG, Leite YLR, Costa LP, Siciliano, S, Kierulff MCM, Mendes SL, Tavares VC, Mittermeier RA, Patton JL (2012) Annotated Checklist of Brazilian Mammals. Occasional Papers in Conservation Biology 6:1-76

Pena HFJ, Marvulo MFV, Horta MC, Silva MA, Silva JCR, Siqueira DB, Lima PACP, Vitaliano SN, Gennari SM (2011) Isolation and genetic characterisation of Toxoplasma gondii from a red-handed howler monkey (Alouattabelzebul), a jaguarundi (Puma yagouaroundi), and a black-eared opossum (Didelphisaurita) from Brazil. Veterinary Parasitology 175(3-4):377-381. doi: 10.1016/j.vetpar.2010.10.015.

Pennisi MG, Marsilio F, Hartmann K, Lloret A, Addie D, Belak S, Boucraut-Baralon C, Egberink H, Frymus T, Gruffydd-Jones T, Hosie MJ, Lutz H, Mostl K, Radford AD, Thiry E, Truyen U, Horzinek MC (2013)Bartonella species infection in cats: ABCD guidelines on prevention and management. Journal of Feline Medicine and Surgery 15(7):563-569. doi: 10.1177/1098612X13489214

Reeves, Will K; Nelder, Mark P; Korecki, James A (2005)Bartonella and Rickettsia in fleas and lice from mammals in South Carolina, U.S.A. Journal of Vector Ecology 30(2):310-315.

Ruiz-Pina HA, Cruz-Reyes A (2002). The opossum Didelphis virginiana as a synanthropic reservoir of Trypanosoma cruzi in Dzidzilche, Yucatan, Mexico. Memorias do Instituto Oswaldo Cruz 97(5):613-620. doi:10.1590/S0074-02762002000500003

Silva BTG, Souza AM, Campos SDE, Macieira DB, Lemos ERS, Fachavo ARM, Almosny NRP (2019) Bartonella henselae and Bartonella clarridgeiae infection, hematological changes and associated factors in domestic cats and dogs from an Atlantic rain forest area, Brazil. Acta Tropica 193:163-8. doi: 10.1016/j.actatropica.2019.02.026

Sousa KCM, Amaral RB, Herrera HM, Santos FM, Macedo GC, Pinto PCEA, Barros-Bettesti DM, Machado, RZ, Andre MG (2018) Genetic Diversity ofBartonella spp. in Wild Mammals and Ectoparasites in Brazilian Pantanal. Microbial Ecology 76(2):544-554. doi: 10.1007/s00248-017-1138-0

Tarragona EL, Zurvera D, Manzoli DE, Correa AI, Delgado AR, Mastropaolo M, Barengo E, Beldomenico PM (2011) Parametros hematologicos de la comadreja overa, Didelphis albiventris (Lund, 1841), de poblaciones silvestres del centro de la Argentina. In Vet 13(2):97-105. 
Zangwill KM (2013) Cat scratch disease and other Bartonella infections. Advances in Experimental Medicine and Biology 764:159-166. doi: 10.2460/javma.2004.224.1270 